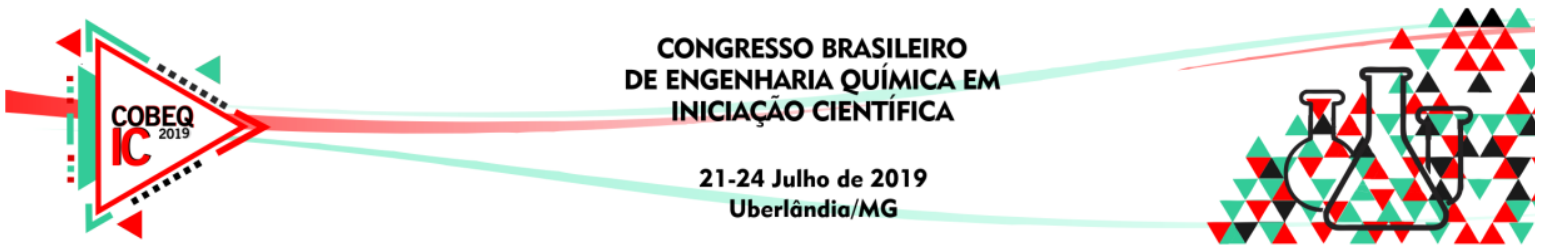

\title{
CONSTRUÇÃO E INSTRUMENTAÇÃO DE UM SECADOR HÍBRIDO FOTOVOLTAICO PARA PROCESSAMENTO DE ALIMENTOS EM PEQUENA ESCALA
}

\author{
M. N. CANDIDO ${ }^{1}$, R. S. AGUIAR ${ }^{1}$, L. F. HIDALGO ${ }^{1,2}$, J. T. FREIRE $^{2}$ e G. N. A. VIEIRA ${ }^{1}$ \\ ${ }^{1}$ Universidade Estadual Paulista "Júlio de Mesquita Filho" (UNESP), Instituto de Química de \\ Araraquara, Departamento de Bioquímica e Tecnologia Química \\ ${ }^{2}$ Universidade Federal de São Carlos (UFSCar), Programa de Pós-graduação em Engenharia \\ Química \\ E-mail para contato: gustavo.vieira@unesp.br
}

\begin{abstract}
RESUMO - Secadores solares híbridos fotovoltaicos são equipamentos que utilizam a radiação solar tanto como fonte de energia térmica, quanto elétrica. Tratase de equipamentos com potencial de aplicação para processar alimentos produzidos por agricultores de pequena escala, melhorando a qualidade final do produto seco em relação à simples exposição à radiação solar direta. Este trabalho teve por objetivo construir um secador solar híbrido fotovoltaico e instalar nele instrumentos de medição para o monitoramento de variáveis de processo (temperaturas, umidades do ar e fluxo de radiação solar incidente). Foi elaborada uma interface digital de aquisição de dados em LabVIEW, que foi testada em dois experimentos distintos: com o uso da placa fotovoltaica para ligar coolers responsáveis pelo escoamento do ar no secador ou sem o seu uso. Verificou-se o funcionamento pleno deste secador e da interface de aquisição de dados.
\end{abstract}

\section{INTRODUÇÃO}

Uma das mais antigas aplicações da radiação solar é em processos de secagem. Trata-se de uma fonte de energia limpa, renovável e de baixo custo, sendo uma alternativa interessante para processos de secagem em pequena escala. No Brasil, a densidade da radiação solar está entre as maiores do mundo, no intervalo de 8 a $22 \mathrm{MJ} / \mathrm{m}^{2} / \mathrm{dia}$, demonstrando enorme potencial energético solar no país (BRASIL, 2008; IMRE, 2006).

Na secagem solar, a exposição direta à radiação térmica pode ser utilizada como única fonte de calor (secagem solar direta) ou para aquecer o ar de secagem (indireta). $\mathrm{O}$ ar pode escoar por convecção natural ou forçada. A convecção forçada pode causar um aumento das taxas de transferência de calor e massa (BELESSIOTIS; DELYANNIS, 2010), se a secagem for limitada por mecanismos externos (predominantemente convectivos), e não internos (predominantemente difusivos). Quando se utiliza a convecção forçada em secadores solares, diz-se que o secador solar é híbrido (IMRE, 2006).

Uma das limitações da secagem solar híbrida é a dependência de energia elétrica para acionar equipamentos como ventiladores e sistemas auxiliares de aquecimento. Em geral, a queda de pressão em secadores solares é relativamente baixa; logo, os equipamentos para o 


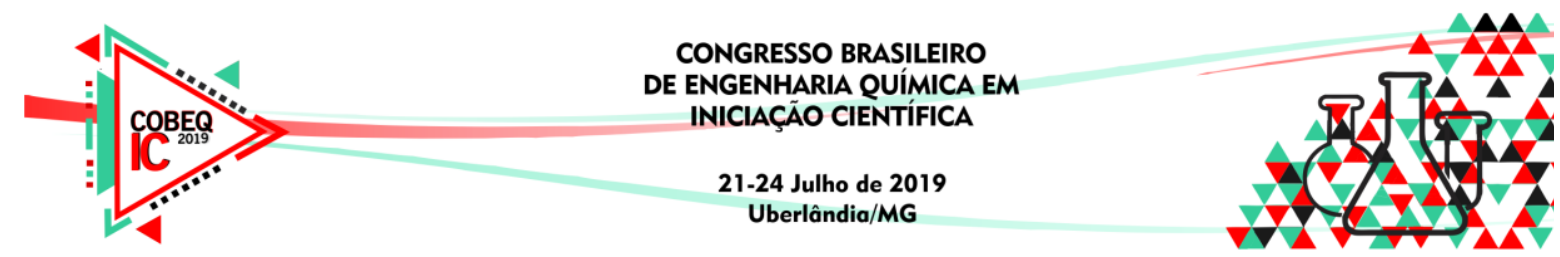

escoamento do ar não necessitam de alta potência, o que viabiliza o uso de energia fotovoltaica. Secadores que combinam o uso de radiação solar com a convecção forçada, sendo esta alimentada por um sistema fotovoltaico, são denominados de secadores solares híbridos fotovoltaicos. Trata-se de uma alternativa para a necessidade de energia elétrica de uma fonte externa (BENNAMOUN, 2013). Diferentes secadores solares híbridos fotovoltaicos têm sido desenvolvidos e aplicados essencialmente na secagem de alimentos (BARNWAL; TIWARI, 2008; EKECHUKWU; NORTON, 1999; NAYAK et al., 2011). Neste contexto, o objetivo deste trabalho foi a construção e a instrumentação de um secador solar híbrido fotovoltaico, que permitirá o processamento de alimentos em pequena escala e a análise deste processo de secagem em etapas futuras.

\section{MATERIAL E MÉTODOS}

Para execução deste trabalho foi construído um secador solar híbrido fotovoltaico, representado esquematicamente pela Figura 1.

Figura 1 -Esquema do secador solar híbrido desenvolvido.
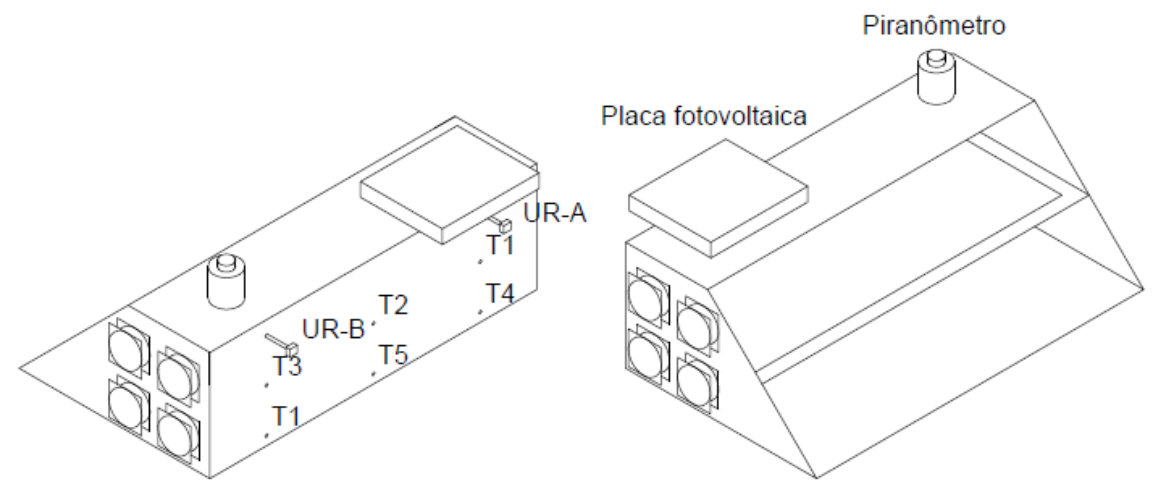

O secador propriamente dito consiste em uma caixa metálica de inox, cujo formato é um prisma de base trapezoidal. A face trapezoidal tem $30 \mathrm{~cm}$ de base menor, $70 \mathrm{~cm}$ de base maior e $40 \mathrm{~cm}$ de altura. Os ângulos da base do trapézio são $90^{\circ}$ (face posterior) e $45^{\circ}$ (face anterior). A largura total do secador é de $1,20 \mathrm{~m}$. Todo o secador está suportado em uma estrutura metálica com rodízios, o que permite transportá-lo para uma área ensolarada.

Sobre a face superior do secador, foi instalada uma placa fotovoltaica de potência nominal de $10 \mathrm{~W}$, tensão máxima de $17,5 \mathrm{~V}$, tensão de circuito aberto de $21,5 \mathrm{~V}$, corrente de curtocircuito de 0,65 A e corrente de circuito aberto de 0,58 A. As dimensões da placa fotovoltaica são $35,5 \mathrm{~cm}$ por $30,0 \mathrm{~cm}$. Ela fornece energia elétrica para oito coolers (tipicamente utilizados em microcomputadores) de $12 \mathrm{~cm}$ de diâmetro nominal, que estão fixados nas faces laterais, de forma a permitir a entrada do ar na câmara por uma das faces e remoção do ar pela outra. A face anterior (inclinada) do equipamento foi construída em vidro temperado e está fixa por dobradiças metálicas na face superior, permitindo a inserção e retirada do material no secador, que pode ser acomodado em uma prateleira metálica perfurada suspensa a $20 \mathrm{~cm}$ da face inferior do secador, ou sobre a própria face inferior. 


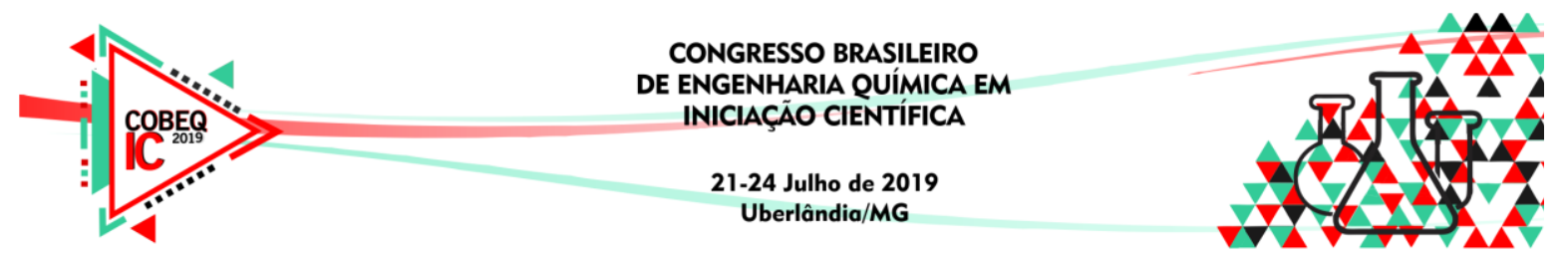

\subsection{Instalação dos medidores e demais periféricos}

Para fins de análise do processo de secagem de alimentos neste secador, foi necessário instalar medidores de variáveis de processos relacionados à radiação solar e à corrente gasosa. Para a medição do fluxo de radiação solar, foi instalado na face superior do secador um piranômentro da marca Hukseflux, modelo SR05-D2A2, que mede o fluxo de radiação solar em um intervalo de 0 a $1600 \mathrm{~W} / \mathrm{m}^{2}$ e converte em um sinal analógico de corrente de 4 a $20 \mathrm{~mA}$. Para a medição da umidade do ar na entrada e na saída do secador (próximo aos coolers), foram utilizados dois transmissores de temperatura e umidade da marca Novus, modelo RHT-DM. Para a medição da temperatura do leito de material dentro do secador, foram instalados seis termopares tipo J, sendo três sobre a prateleira perfurada e três na face inferior. Os termopares foram instalados para permitir a medição função da posição ao longo da largura do secador.

Todos os medidores foram conectados a uma placa de aquisição de dados da marca National Instruments, modelo cDAQ-9185, com os módulos de temperatura (NI 9212) e de entrada analógica (NI 9203). Para monitoramento das variáveis, foi elaborada uma rotina de aquisição de dados no software LabVIEW 2018. A rotina (virtual instrument, ou VI) permitiu que a aquisição fosse feita automaticamente em intervalos de tempo determinados pelo usuário.

\subsection{Testes preliminares}

Com a instrumentação concluída, testou-se o funcionamento do equipamento e da interface de aquisição de dados em dois experimentos. No primeiro experimento, o secador foi exposto à radiação solar, com a placa de vidro voltada à direção norte, e a convecção forçada foi utilizada (coolers ligados). O segundo experimento foi realizado da mesma forma, mas sem a convecção forçada (coolers desligados). Nenhum material foi alimentado no secador em ambos os experimentos, portanto, não houve processo de secagem. Os experimentos foram realizados no período das $9 \mathrm{~h}$ às $16 \mathrm{~h}$, nos dias 03 e 05 de abril de 2019 , no município de Araraquara-SP. Neste intervalo de tempo, todas as variáveis descritas anteriormente foram medidas periodicamente de forma automática pela rotina LabVIEW a cada $30 \mathrm{~s}$. Cada ponto experimental equivale à média de 500 pontos medidos com uma frequência de $1,0 \mathrm{kHz}$.

\section{RESULTADOS E DISCUSSÃO}

A Figura 2 mostra uma captura de tela da interface da rotina de aquisição de dados desenvolvida no software LabVIEW. Verifica-se que a rotina permitiu o monitoramento contínuo das variáveis do processo: as temperaturas 1 a 6 , o fluxo de radiação solar e as temperaturas e umidades do ar na entrada (A) e na saída (B). As duas caixas na porção inferior da interface foram utilizadas para salvar a média e o desvio-padrão de 500 medidas obtidas a $1,0 \mathrm{kHz}$ de forma pontual (lado esquerdo) ou periodicamente, com um intervalo de tempo determinado pelo usuário (lado direito). Todos estes dados foram salvos em um arquivo *.txt em uma pasta também especificada pelo usuário nesta interface.

A interface desenvolvida é baseada em uma rotina criada na forma de diagrama de blocos (na linguagem LabVIEW), que foi suprimida para fins de síntese deste trabalho. No entanto, a elaboração da rotina propriamente dita foi uma etapa essencial para que seja possível a aquisição de dados durante experimentos de secagem a serem realizados futuramente. 

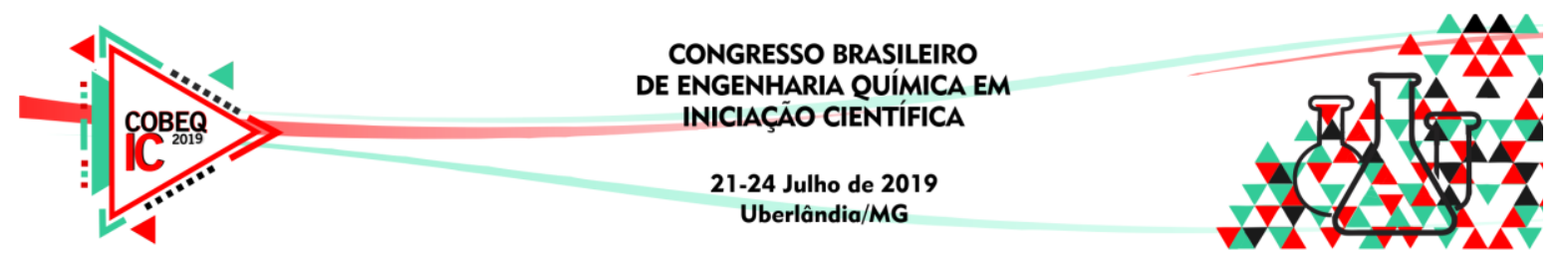

Figura 2 - Interface ao usuário da rotina de aquisição de dados desenvolvida em LabVIEW

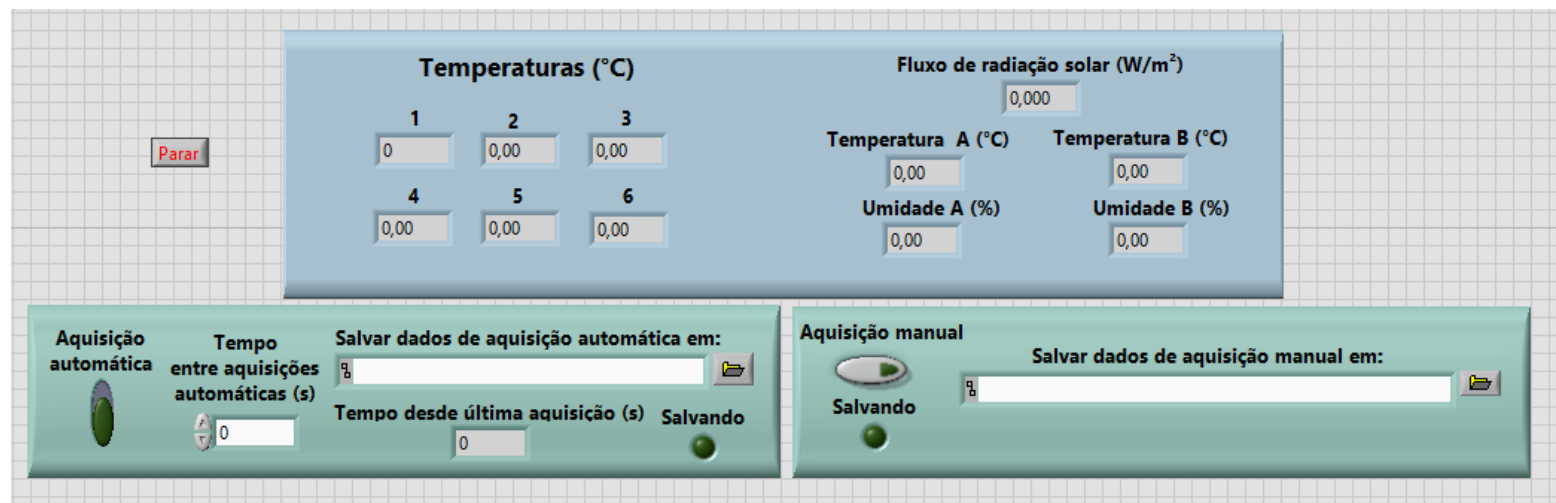

Como exemplo de conjunto de dados obtidos por esta rotina, a Figura 3 mostra o perfil de temperaturas 1 a 6 (Figura 3 (a)) e as umidades relativas do ar na entrada e na saída (Figura 3 (b)) em função do tempo no experimento com os coolers ligados, e o fluxo de radiação solar em função do tempo (Figura 3 (c)) para ambos os experimentos.

Todas as variáveis monitoradas apresentaram variações, decorrentes da periodicidade natural da radiação solar, o que pode ser verificado principalmente na Figura 3 (c). No início, o fluxo de radiação solar foi mais baixo, já que o horário era próximo do alvorecer. No período próximo do final da manhã e no início da tarde (entre 3 e $4 \mathrm{~h}$ de experimento), são notadas em linhas gerais as temperaturas máximas em todas as posições e o máximo do fluxo de radiação solar; enquanto próximo ao final do experimento (ao entardecer), as temperaturas e o fluxo de radiação solar diminuem, como esperado. As reduções bruscas de fluxo de radiação solar estão relacionadas com a formação de nuvens no período. Já as variações de umidade relativa estão exclusivamente relacionadas a variações climáticas, visto que não estava ocorrendo processo de secagem em ambos os experimentos.

Figura 3 - Temperaturas (a), umidades relativas do ar (b) e fluxo de radiação solar (c) em função do tempo

(a)

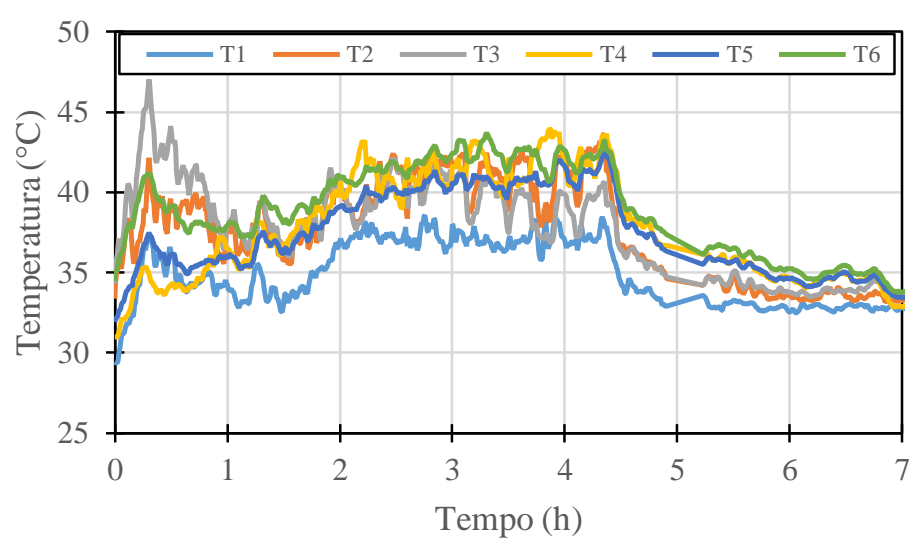


(b)

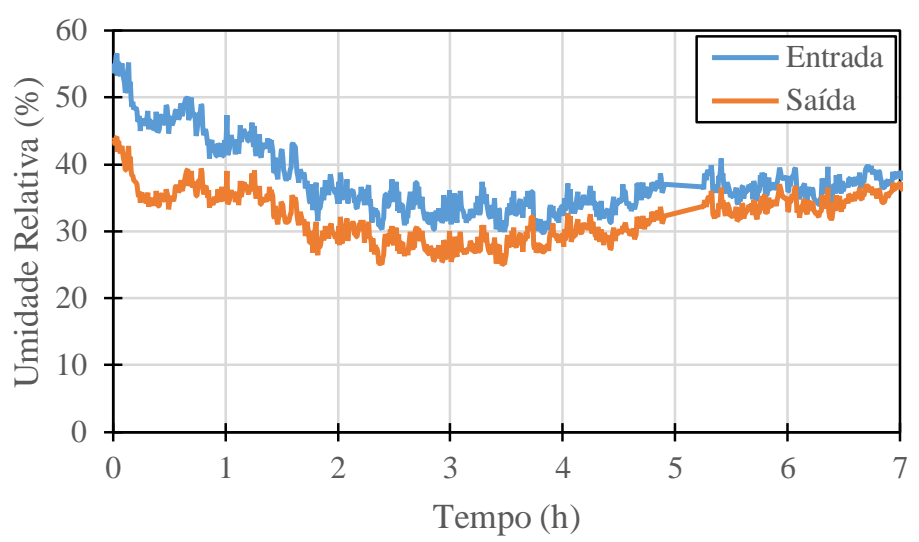

(c)

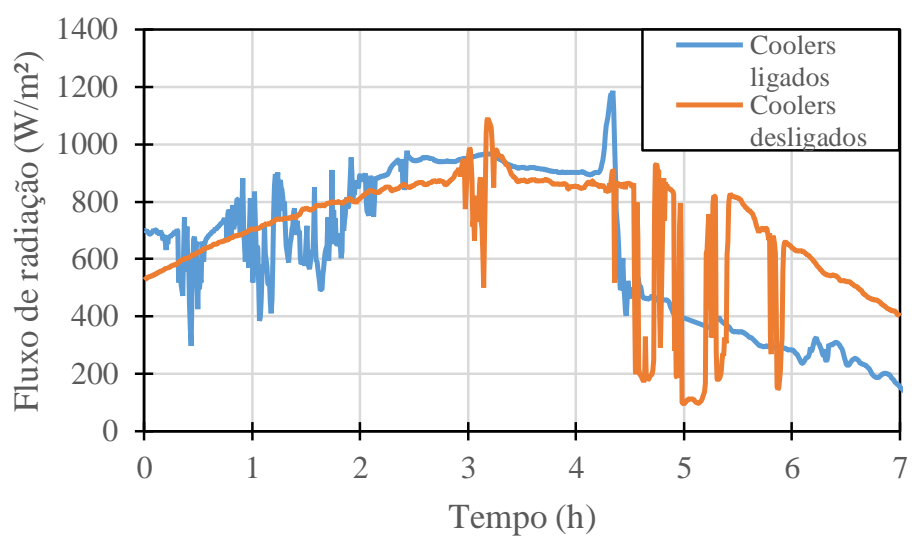

A tendência nas medições de temperaturas e umidades relativas foi a mesma do ponto de vista qualitativo para os experimentos com os coolers desligados. Porém, houve diferenças quantitativas nos resultados. A Tabela 1 mostra a média e o desvio-padrão das medidas ao longo do tempo, para as seis posições, em ambos os experimentos.

Tabela 1 - Médias e desvios-padrão das temperaturas nas seis posições dos termopares, para ambos os experimentos

\begin{tabular}{|c|c|c|c|c|c|c|c|c|}
\cline { 3 - 9 } \multicolumn{1}{c|}{} & \multicolumn{7}{c|}{ Temperaturas $\left({ }^{\circ} \mathrm{C}\right)$ e posição dos termopares } \\
\hline \hline \multicolumn{2}{c|}{ Coolers } & 1 & 2 & 3 & 4 & 5 & 6 & Média \\
\hline \multirow{3}{*}{ Ligados } & Média & 34,9 & 37,7 & 37,8 & 37,8 & 37,5 & 39,0 & 37,7 \\
\cline { 2 - 10 } & Desvio & 2,0 & 3,0 & 2,9 & 3,2 & 2,6 & 2,8 & 1,4 \\
\hline \multirow{3}{*}{ Desligados } & Média & 60,5 & 66,9 & 55,7 & 47,9 & 48,3 & 46,4 & 54,3 \\
\cline { 2 - 9 } & Desvio & 11,8 & 11,0 & 9,0 & 7,1 & 5,6 & 4,7 & 8,2 \\
\hline
\end{tabular}

A média de todas as temperaturas ao longo do secador foram superiores para o experimento com os coolers desligados em relação ao experimento com os coolers ligados. $\mathrm{O}$ resultado era esperado, já que a constante retirada de ar do secador pelos coolers da saída também corresponde à constante retirada de energia térmica do sistema (na forma de entalpia 


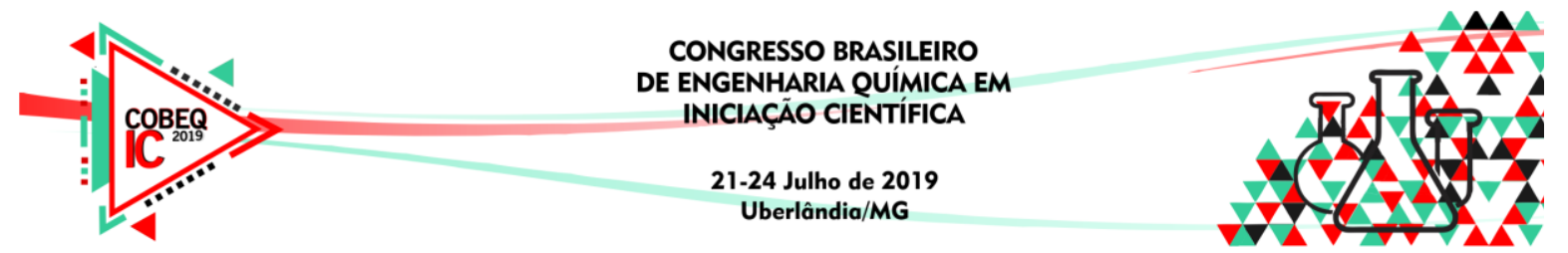

do ar na saída), reduzindo a taxa de acúmulo de energia no secador. Além disso, nota-se que os desvios-padrão são superiores para o experimento com coolers desligados em relação ao experimento com os coolers ligados. Trata-se também de um resultado esperado, visto que a convecção forçada auxilia na redução de gradientes de temperatura no secador.

A princípio, processos de secagem com convecção forçada ocorrem a taxas de secagem mais elevadas (se o processo for controlado por mecanismos externos). Por outro lado, a redução da temperatura no secador com os coolers ligados pode desfavorecer cineticamente o processo de secagem, por reduzir as taxas de transferência de calor. Experimentos posteriores de secagem permitirão concluir se é vantajosa ou não a utilização da convecção forçada.

\section{CONCLUSÃO}

A partir dos dados mostrados, conclui-se que o secador solar híbrido fotovoltaico construído e instrumentado apresenta-se em funcionamento pleno; assim, será possível a realização de experimentos de secagem de diferentes materiais. Porém, a redução da taxa de acúmulo de energia no secador com o uso da convecção forçada poderá causar uma redução na taxa de secagem. Outros experimentos serão realizados para verificação destas hipóteses.

\section{AGRADECIMENTOS}

Os autores agradecem o apoio financeiro da FAPESP (processos 2017/21890-5, 2018/23766-2, 2018/24132-7 e 2018/23762-7). As opiniões, hipóteses e conclusões ou recomendações expressas neste material são de responsabilidade dos autores e não necessariamente refletem a visão da FAPESP.

\section{REFERÊNCIAS}

BARNWAL, P.; TIWARI, G. N. Grape drying by using hybrid photovoltaic-thermal (PV/T) greenhouse dryer: An experimental study. Solar Energy, v. 82, p. 1131- 1144, 2008.

BELESSIOTIS, V.; DELYANNIS, E. Solar drying. Solar Energy, v. 85, p. 1665-1691, 2010.

BENNAMOUN, L. Integration of Photovoltaic Cells in Solar Drying Systems. Drying Technol.. v. 31, p. 1284-1296, 2013.

BRASIL. Agência Nacional de Energia Elétrica (ANEEL). Atlas da Energia Elétrica do Brasil. 3 ed. Brasília: ANEEL, 2008, p. 85.

EKECHUKWU, O. V.; NORTON, B. Review of solar-energy drying systems II: an overview of solar drying tecnology. Energ. Convers.Manage., v. 40, p. 615-655, 1999.

IMRE, L. Solar Drying. In: MUJUMDAR, A. S. (Ed.) Handbook of Industrial Drying, 3 ed., Boca Raton: Taylor \& Francis, Inc., p. 308-361, 2006.

NAYAK, S.; KUMAR, A.; MISHRA, J.; TIWARI, G. N. Drying and testing of mint (Mentha piperita) by a hybrid photovoltaic-thermal (PVT)-based greenhouse dryer. Drying Technol., v. 29, p. 1002-1009, 2011. 